University of Nebraska - Lincoln

DigitalCommons@University of Nebraska - Lincoln

Agronomy \& Horticulture -- Faculty Publications

Agronomy and Horticulture Department

2005

Standard Meteorological Measurements

\author{
Kenneth Hubbard \\ University of Nebraska-Lincoln, khubbard1@unl.edu \\ Steven E. Hollinger \\ University of Illinois at Urbana-Champaign, hoboinc87@comcast.net
}

Follow this and additional works at: https://digitalcommons.unl.edu/agronomyfacpub

Hubbard, Kenneth and Hollinger, Steven E., "Standard Meteorological Measurements" (2005). Agronomy \& Horticulture -- Faculty Publications. 695.

https://digitalcommons.unl.edu/agronomyfacpub/695

This Article is brought to you for free and open access by the Agronomy and Horticulture Department at DigitalCommons@University of Nebraska - Lincoln. It has been accepted for inclusion in Agronomy \& Horticulture -Faculty Publications by an authorized administrator of DigitalCommons@University of Nebraska - Lincoln. 


\title{
Standard Meteorological Measurements
}

\author{
K. G. HUBBARD \\ University of Nebraska \\ Lincoln, Nebraska \\ S. E. HOLLINGER \\ Illinois State Water Survey \\ Champaign, Illinois
}

Instruments that measure weather variables have been invented and tested since the time of Leonardo de Vinci. The earliest instruments were crude by today's standards and required manual observation and notation of the weather variable of interest. In recent years, the miniaturization of circuits-sensors and the use of electronic processors have made it possible to collect ever-increasing numbers of observations on scales not previously considered.

In many agricultural applications, the primary portion of the atmosphere that is of interest is the lower planetary boundary layer, or that layer affected by the earth's surface. Accurate measurement of weather variables in the lower planetary boundary layer requires an understanding of the interactions among the atmosphere, plant communities, and soils.

Temperature and pressure are often measured because of their role in air movement and energy exchange between the earth's surface and the atmosphere. Temperature is perhaps of greater interest in agricultural applications because it is a driving variable that determines the rate of growth and development of an organism, and thus determines what species can grow in a region. Wind speed and direction are measured because of their role in convective energy exchange and the movement of spores, pollen, odors, and chemicals as they drift in the atmosphere. Precipitation amount, intensity, frequency, and form are important in determining the availability of water for crops and play an important role in soil erosion by water and in water quality issues. Solar radiation and relative humidity are additional weather variables, important to agriculture, that are often measured by appropriate sensors at automated weather stations. These variables will be discussed by Klassen and Bugbee (2005, this volume) and Campbell and Diak (2005, this volume).

In the past two centuries, official records of the weather were first kept by explorers such as Lewis and Clark, by the military at forts on the frontier, and more recently by governmental agencies such as the U.S. Weather Bureau and its

Copyright @2005. American Society of Agronomy, Crop Science Society of America, Soil Science Society of America, 677 S. Segoe Rd., Madison, WI 53711, USA. Micrometeorology in Agricultural Systems, Agronomy Monograph no. 47. 
successor, the National Weather Service. Records of past weather conditions in the USA are archived at the National Climatic Data Center in Asheville, NC.

In the late 1800s, the land grant universities began to coordinate the collection of data from state networks. Beginning in 1896, these networks were merged and weather observations were taken by a resulting network of National Weather Service Cooperative Observers throughout the USA. Many of these weather stations are located in rural areas or small towns. The volunteer observers have recorded air temperature and precipitation on a daily basis and observations have been used mainly for agricultural purposes. Before the rapid growth of the airline industry in the 20th century, the cooperative observer network was a part of the U.S. National Weather Service (then known as the Weather Bureau) and during that time was housed in the U.S. Department of Agriculture.

In the 1960s, the Weather Bureau became a part of the Department of Commerce and became known as the National Weather Service. A major customer of weather data in the later part of the 20th century was the aviation industry. Therefore, many weather stations are located at airports. The establishment of weather stations at the airports, where personnel could take manual observations throughout the day, resulted in the routine monitoring of additional weather variables. At many airport sites, wind speed and direction, barometric pressure, relative humidity, and cloud cover and height were taken in addition to the temperature and precipitation measurements.

Before the last quarter of the 20th century, the National Weather Service Cooperative Network and weather stations located at major airports provided most of the weather observations and climate data sets in the USA. Recent innovations in satellite monitoring, doppler radar, lightning detection, and Automated Surface Observing Systems (ASOS) have provided new nationwide data sets. A brief description of the ASOS network can be found in Friday (1994). The ASOS User's Guide (1998) can be viewed on the Internet at http://205.156.54.206/asos/.

State and regional automated weather station (AWS) networks have been developed in the past few decades (Meyer \& Hubbard, 1992). The stations are generally located at agricultural research stations, branch campuses, or other locations within a region. These networks are the result of the development of relatively low-cost automated weather stations that measure and record standard meteorological variables (Tanner, 1990). Many of the AWS networks were created to provide weather data to support information technology in agriculture. Measurements typically made at such stations include air temperature, relative humidity, wind speed and direction, precipitation, solar radiation, and sometimes soil temperature at selected depths. Other sensors related to agricultural and environmental applications, such as ultraviolet (UV) radiation sensors, photosynthetically active radiation (PAR) sensors, soil temperature and soil moisture sensors, and atmospheric trace gas sensors $\left(\mathrm{CO}_{2}\right.$ and other gas sensors), have the potential to be introduced into the AWS networks in the future. The new AWS data assists agricultural producers in making strategic and tactical decisions related to, for example, irrigation scheduling, crop selection, pest management, and livestock and forest management. The data collected from the AWS networks also allow producers and agricultural decision makers to use modern decision-making tools such as crop models, climate change models, and decision support systems that 
require both near real time and historical weather records. Planning and operational details for stations of this type (e.g., sensor placement, data handling) can be found in Brown and Hubbard (2001), Hubbard (2001a,b), Hubbard and Sivakumar (2001), and Hollinger et al. (1994).

Some states also have networks dedicated to transportation needs, with stations located along selected highways, mostly near bridges and overpasses, throughout the state (AASHTO, 1999). Since the data needs differ from those of agricultural users, the measured variables and placement of sensors also differ; however, these data can be useful for non-transportation purposes in the absence of other data sources. A description of a typical transportation weather network has been provided by Edwards (1998).

The purpose of this chapter is to provide a background on air temperature, precipitation, barometric pressure, wind speed and direction, cloud cover fraction, and ceiling height measurements. For each of the weather variables we will discuss (i) a brief history and the theory and fundamentals of measurement; (ii) the calibration, placement, and maintenance of the instruments; (iii) procedures for quality control-assurance and error analysis; and (iv) examples of valueadded processing (changing data into information) applicable to agricultural systems.

\section{WORKING DEFINITIONS}

Sensors are characterized according to terminology that describes their performance. Some terms frequently encountered and working definitions are:

accuracy: a measure of how the true value of the atmospheric variable compares with the measured value

calibration: identification of a scientific scale that is associated with particular sensor readings

linearity: the maximum deviation of the calibration curve from a best fit line divided by the full range of the sensor

precision: a measure of the scatter of points relative to the calibration curve

range: upper and lower values of the variable, or limits beyond which the sensor should not be used

reproducibility: the ability of a sensor to reproduce a measurement when exposed to the same environment(s)

sensitivity: the slope of the calibration curve

stability: the extent to which a sensor holds its calibration

\section{METEOROLOGICAL SENSORS}

The characteristic that all meteorological sensors have in common is that a property of the sensor responds in a known and predictable fashion as changes occur in the atmospheric variable of interest. This tendency for the sensor to act as an analog to the atmospheric variable is at the heart of sensor performance. 
The sensor output (property) that responds to the atmospheric variable of interest might be (i) resistance or capacitance (e.g., resistance temperature sensor, capacitive barometric pressure sensor), (ii) analog voltage or current (e.g., wind speed cup or propeller, wind direction vane, weighing bucket rain gauge), (iii) pulsing or switching (e.g., cup anemometer, tipping bucket rain gauge), and (iv) digital output in the new intelligent sensors (usually microprocessor-based, e.g., cloud height sensor system, two-dimensional sonic anemometer).

According to Hauptmann (1993), the performance of a sensor system should be judged as follows: it should have (i) sensitivity adequate for the application for the desired measurement; (ii) a high degree of accuracy and reproducibility; (iii) linearity (author's note: it is not so important to have a linear response with modern data logging equipment); (iv) dynamic range large enough to provide the desired precision and to span the expected values of the variable being measured; (v) no response to interference and environmental influences; (vi) a high degree of stability and reliability; and (vii) a long life expectancy with low maintenance requirements.

Older weather sensors generally produced an analog output that an observer noted and manually recorded at specified observation times. An example is a mercury-in-glass thermometer. The number of observations that could be recorded by these systems was limited by the manpower available to monitor the instruments. Modern sensors are either continuously or regularly monitored by a data logger or computer with an analog to digital converter. The observations are stored on the data logger or computer disk or memory and downloaded to a central location for analysis and use. The frequency of observations is limited only by the speed of the computer, the number of sensors monitored during each cycle of sensor interrogation, and the time required to interrogate these sensors. Data loggers and computers can generally monitor a number of instruments more than once a second $(1 \mathrm{~Hz})$.

\section{AIR TEMPERATURE}

\section{History}

A detailed history of the thermometer and its use in meteorology is presented by Middleton $(1966,1969)$. Briefly, temperature measurement by thermometers has progressed from the first primitive air thermometer in the early 1600 s to the precision instruments available today.

One of the earliest references to the concept of degrees of heat and cold was made by the Greek physician Galen (Middleton, 1969). A precursor to the thermometer, the thermoscope, was developed as a result of pneumatic experiments performed during the second century B.C. by Philo of Byzantium, and in the first half of the first century B.C. by Hero of Alexandria (Middleton, 1966). Hero's work was published in Latin in 1575 and later in Italian. The first thermometers were air thermometers invented around 1612 to 1615 . Middleton (1966) identifies Galileo, Santario, Drebbel, and Fludd as possible inventors of the air thermometer, and the Grand Duke of Tuscany, Ferdinand II, as the inven- 
tor of the liquid-in-glass (LIG) thermometer in ca. 1641. The earliest LIG thermometers used alcohol as the liquid. Mercury thermometers were tested as early as 1657 , but abandoned because the mercury did not rise as high in the column as the alcohol, even though it responded faster than alcohol to a change in temperature.

LIG thermometers were used in the first known network of temperature observations established in 1654. These thermometers were "50-degree instruments" with the ice point at $13.5^{\circ}$. At the same time, 100-degree and 300-degree thermometers existed, but before the advent of standard thermometer scales, there was no way to compare the reading among the different thermometers. Each thermometer maker used their own methods for construction of thermometers. With no standard scale there was no calibration of thermometers, and thermometers made by different craftsmen could not be compared. Although the melting temperature of snow was often used as a single fixed point, there was generally no second fixed point. It was not until the development by Fahrenheit (ca. 1724) and Celsius (ca. 1742) of temperature scales that the freezing and boiling points of water were used to determine thermometer scales. The Celsius scale, when first developed, had $0^{\circ}$ as the boiling point of water and $100^{\circ}$ as the freezing point. It is generally accepted that Märten Strömer, Celsius' successor, inverted the scale so that $0^{\circ}$ was the freezing point and $100^{\circ}$ was the boiling point.

LIG thermometers are still in use in the early 21 st century. In the USA, LIG thermometers were commonly used through most of the past century, in the National Weather Service's Cooperative Observer Network, where maximum (mercury in glass) and minimum (alcohol in glass) thermometers were used (see LIG maximum and minimum thermometer in Fig. 1-1). More recently the LIG thermometers were replaced with an electronic thermometer called the Maximum Minimum Temperature System (MMTS).

The first thermometers were constructed to measure the change in the volume of a fluid (air, alcohol, mercury) with a change in temperature. During the

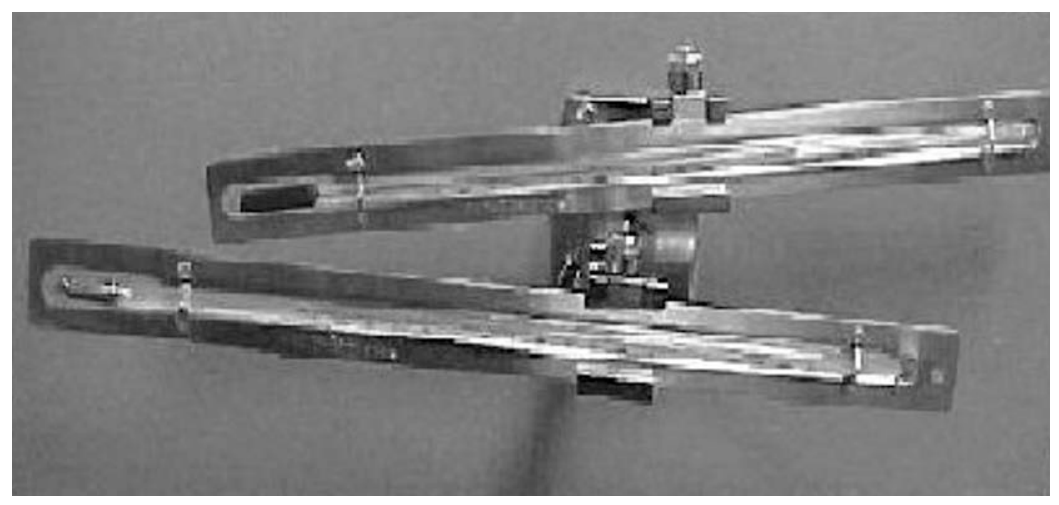

Fig. 1-1. Liquid in glass (LIG) thermometers for measuring maximum and minimum temperatures. 
mid-1700s the first thermometers using the principle of deformation of a material were made. The earliest consisted of two dissimilar metals fastened together at one end while the opposite ends were connected to levers to indicate the temperature. Bimetallic thermometers consisted of two different metals with different expansion coefficients riveted or soldered together. As the temperature changed the bimetal strip would bend indicating the change in temperature. A third deformation thermometer consists of a liquid inside a metallic system. As the liquid expands or contracts with temperature changes the metallic container is deformed. The most famous of this type is the Bourdon thermometer. In modern meteorological usage, the thermograph is the most common use of this technology. With the advent of data loggers, electronic thermometers are replacing LIG and bimetallic thermometers; however, these instruments are still frequently used in developing countries around the world.

In the early 1800 s, the discovery was made that two dissimilar metal strips, when joined at the ends, would produce an electric current in the loop, if the temperatures at the two junctions were different. This resulted in a new type of thermometer, the thermocouple, and offered a means of measuring temperature by an electric current. Because very small junctions can be made, the time constant of the instrument is very small so that rapid changes in temperature can be accurately measured.

In 1821, Sir Humphry Davy showed the dependence of the electrical resistance of metals on temperature. This principle was suggested by Carl Wilhelm Siemens, in ca. 1871, as a possible method of measuring temperatures. Platinum resistance thermometers were used as early as 1896 and are still in use today. They are generally the instrument of choice in remote locations where they are monitored by data loggers or when high precision is desired.

\section{Principal of Operation}

Temperature sensors commonly used for measuring air temperature are the platinum resistance temperature detector (PRTD), thermistors, and thermocouples (Fig. 1-2). The PRTD sensing element is usually a coil of fine wire or a metal film constructed of platinum. The general relationship between the resistance of the PRTD and the temperature is

$R=R_{0}\left(1+A T+B T^{2}+C(T-100) T^{3}\right)$

where $R$ is resistance (ohms) of the PRTD at the temperature $T\left({ }^{\circ} \mathrm{C}\right)$ and $R_{\mathrm{o}}$ is the nominal resistance of the PRTD at $0^{\circ} \mathrm{C}$ (e.g., typical values are 100, 200, or 1000 ohms). The constants $A, B$, and $C$ are calibration coefficients from the manufacturers. For AWS applications, the temperature measuring range is relatively narrow, from -50 to $+50^{\circ} \mathrm{C}$, so that the coefficient $C$ may be ignored. The PRTD sensor is widely used in the existing air temperature systems including the ASOS temperature sensor, R.M. Young ${ }^{1}$ temperature sensor (R.M Young, Traverse City, MI) and Vaisala HMP45C sensor (Vaisala Inc., Woburn, MA).

\footnotetext{
${ }^{1}$ Mention of vendor names here and elsewhere in this chapter is for the convenience of the reader and does not constitute endorsement of a particular product.
} 


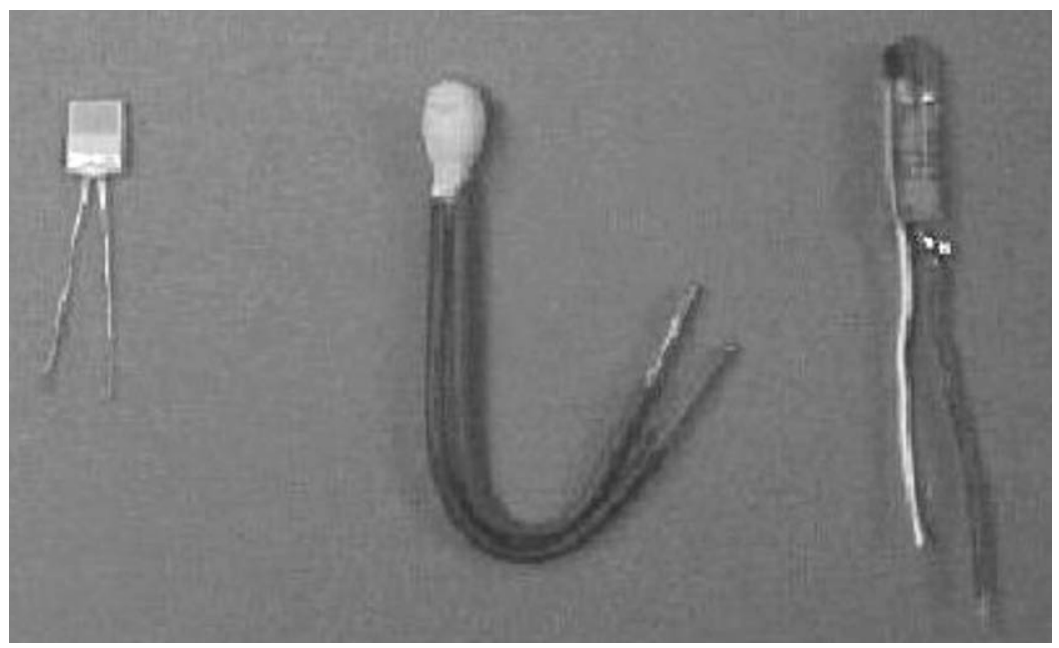

Fig. 1-2. Examples of temperature sensors: precision resistance temperature device (left), thermocouple (middle), and thermistor (right).

Like the PRTD, the thermistor also is widely used in air temperature measurements at AWS. Thermistors are generally composed of semiconductor materials. Although positive temperature coefficient units are available, most thermistors have a negative temperature coefficient (NTC); i.e., their resistance decreases with increasing temperature. An individual thermistor temperature is related to resistance by use of the Steinhart-Hart equation (Steinhart \& Hart, 1968):

$$
\frac{1}{T}=A+B \ln R+C(\ln R)^{3}
$$

where $A, B$, and $C$ are curve-fitting constants, $T$ is a temperature with Kelvin degree $\left({ }^{\circ} \mathrm{K}\right)$, and $R$ is resistance (ohms) of the thermistor at temperature $T\left({ }^{\circ} \mathrm{K}\right)$. Thermistor sensors are used in the MMTS temperature sensor (RMS Technology, Inc., Newport News, VA), Campbell 107 temperature sensor (Campbell Scientific, Inc., Logan, UT), and Vaisala HMP35C air temperature sensor (Vaisala Inc., Woburn, MA).

Although the thermocouple is rarely used in AWS, it is a common temperature sensor in research projects. Any pair of thermoelectrically dissimilar wires can be used as a thermocouple. The wires need only be joined together at one end (measuring junction) and connected to a voltage-measuring instrument at the other end (reference junction) to form a usable system. Whenever the measuring junction is at a different temperature than the reference junction, a Seebeck voltage [electromotive force $(\mathrm{EMF})$ ] will develop that is related to the temperature difference between the two junctions. The common types of thermocouples available commercially include Type E [Nickel-Chromium (+) versus Constantan (-)], Type J [Iron (+) versus Constantan (-)], Type K [Nickel-Chromium (+) versus 
Nickel (-)], and Type T [Copper (+) versus Constantan (-)]. The voltage-to-temperature conversion relation when the reference junction is kept at $0^{\circ} \mathrm{C}$ is

$T=a_{0}+a_{1} x+a_{2} x^{2}+a_{3} x^{3}+\ldots+a_{\mathrm{n}} \mathrm{x}^{\mathrm{n}}$

where $T$ is the temperature and $x$ is the thermocouple voltage. The polynomial coefficients $a_{1}, a_{2}, \ldots$, and $a_{\mathrm{n}}$ are unique to each thermocouple type. The maximum order of the polynomial $(n)$ depends on the measuring temperature range and thermocouple type.

In the electronic measurement of air temperature, it is necessary to convert the sensor output into a temperature reading. For the PRTD and thermistor sensors, the half bridge or full bridge circuitry is commonly selected for the signal conditioning. The constant current excitation for the bridge circuit is better than the constant voltage excitation for resistance measurements. For a more complete discussion of signal conditioning circuits, please see Dally et al. (1984). It is best if the output voltage is measured twice: once with current in one direction and again with the current in the opposite direction. Taking the average of the two readings in this approach cancels errors from driving current (excitation reference) imprecision, unwanted voltage offsets, and EMF. Modern data loggers can provide this switching and averaging automatically under program control.

The thermocouple voltage measurement is very straightforward, but both magnitude and sensitivity of the output signal from the thermocouple are relatively small. The signal conditioning circuitry design must provide an accurate reference junction (cold junction) temperature measurement or compensation by hardware circuits. Some data loggers include an internal thermistor or PRTD temperature sensor below the input terminals that can serve as a reference temperature for thermocouple temperature measurement. Therefore, maintaining uniform temperature at the input terminals of this type of data logger is necessary for accurate measurements.

Errors in air temperature measurements include the sensor error, data logger errors, and errors due to incomplete coupling between the sensor and the air. For the resistance measurements of air temperature, the stability of excitation source, extension lead (thermal conduction and lead resistance), sensor selfheating, and extra EMF from improper wire connections are sources of error. The errors caused by sensor and data logger uncertainties are usually less than $\pm 0.5^{\circ} \mathrm{C}$. Some specifications that should be considered when using the above temperature sensors are listed in Table 1-1.

\section{Use of Temperature Sensors}

Accurate air temperature measurements depend on careful calibration, placement, and maintenance of the sensor. In selecting the temperature sensor, the accuracy, precision, frequency and use of the temperature observation should be considered. When the relationship between time and temperature is important, it is necessary to take account of the time constant (time lag) of the instrument. Relatively, large LIG thermometers have larger time constants (approaching 1 min) compared with the PRTD (10 s), thermocouple sensors (a few seconds), and thermistors (fractions of a second). 
Table 1-1. The typical characteristics of temperature sensors.

\begin{tabular}{llll}
\hline & PRTD & Thermistor & Thermocouple \\
\hline Sensitivity & $0.4 \mathrm{ohms}{ }^{\circ} \mathrm{C}^{-1}$ & $0.1-1.5 \mathrm{kohms}{ }^{\circ} \mathrm{C}^{-1}$ & $0.04-0.06 \mathrm{mv}{ }^{\circ} \mathrm{C}^{-1}$ \\
Stability & Excellent & Good & Excellent \\
Linearity & Slightly nonlinear & Very nonlinear & Slightly nonlinear \\
Response time & $10 \mathrm{~s}$ & $5 \mathrm{~s}$ & $<5 \mathrm{~s}$ \\
Calibration interval & $1 \mathrm{yr}$ & $1 \mathrm{yr}$ & $<1 \mathrm{yr}$ \\
Excitation & Required & Required & No \\
Temperature reference & No & No & Required \\
Signal conditioning & Moderate & Easy & Moderate \\
Cost & High & Medium & Low \\
Advantages & High stability & High sensitivity & Low cost \\
& Robusstness & Ease of signal & fast response time \\
& & conditioning & \\
Disadvantages & Relatively high cost & Nonlinear & Many possible \\
& & & sources of error \\
& Lead wire effects & Exchangeability errors & Need for reference \\
\hline
\end{tabular}

\section{Calibration}

Calibration of air temperature sensors should be conducted with known points of reference. These points are usually produced by using standards that are traceable to the National Institute of Standards and Technology (NIST), standard temperature baths, or NIST traceable dry-well calibrators. The calibration can be a source of error if improper calibration equipment is used. While calibrating the sensors, the time constant (Fritschen \& Gay, 1979) of the sensor should be determined by subjecting the sensors to step changes in temperature and frequently recording the temperature while the sensor comes to equilibrium with the new temperature environment. The calibration standard may have a significant time constant as well and adequate time should be allowed to reach equilibrium at each target temperature. When the temperatures of the candidate sensor and the standard are plotted for different equilibrium conditions, a calibration graph is formed and a best fit procedure can then be employed to derive the calibration equation.

\section{Placement}

It is important to remember that temperature sensors always measure the temperature of the sensor. Only under thermal equilibrium (complete coupling between air temperature sensor and atmosphere) does the sensor temperature represent air temperature. Air temperature sensors should be placed inside a radiation shield that blocks solar radiation and minimizes the short- and long-wave radiation effects on the sensor while maintaining adequate ventilation to ensure complete coupling with the air. The effect of short- and long-wave radiation on a temperature sensor is called radiation loading. Radiation loading occurs whenever the sensor is exposed directly to a radiation source, in this case the sun.

The radiation shields also protect the sensor from being exposed to the cold night sky, which results in radiation cooling of the sensor and gives a temperature reading cooler than the air. Aspirated radiation shields reduce the errors caused by solar radiation and infrared radiation effects but require more power consump- 
tion at the site. The errors caused by incomplete coupling with atmosphere for a non-aspirated shield can reach up to 2 to $4^{\circ} \mathrm{C}$ under calm conditions with fresh snow underlying the surface and high global solar radiation (Marshall \& Woodward, 1985; Tanner, 1990; Lin, 1999).

Exposure of the temperature sensor should be such that water vapor does not condense on the sensor. This is particularly important when using aspirated shields, since water evaporation from the sensor will lower the temperature and underestimate the "dry bulb" temperature of the air.

\section{Maintenance}

Temperature sensors that generate electronic signals should be kept clean from air pollutants and dust. This is especially true of hygroscopic pollutants that capture water vapor. As water vapor condenses onto the sensor, latent heat will increase the temperature of the sensor above the air temperature, and the cooling associated with evaporation will decrease the temperature of the sensor below the air temperature. Sensors at isolated stations cannot be compared with sensors at neighboring stations and therefore should be visited at least monthly and the sensor compared with a standard instrument that is NIST traceable. The radiation shields also should be kept clean to reduce the solar load caused when dust reduces the albedo of the shield.

LIG thermometers should be checked regularly to ensure the mercury liquid column has not separated. If the liquid is separated it can be joined by holding the thermometer vertically in one fist and gently tapping the fist against the palm of the other hand.

\section{Quality Assurance-Quality Control}

A test or a series of tests performed on the temperature data collected is known as quality control or quality assurance. When the data fail the test(s), technical support personnel are informed so that corrective action can be taken as needed. A limit test is often used to examine whether the data fit within previously observed temperature extremes for the site (or vicinity). A rate of change limit can also be included to ensure that temperature changes are within reason. For example, a zero rate of change for more than a few hours may mean that the sensor is no longer responding to the environment. Single station quality control procedures are discussed in more detail by Meek and Hatfield (2001). Other tests become possible when a second temperature sensor of the same type is installed at the station or at a nearby station. In such cases the degree of correlation between the two resulting data sets determines the probability level associated with given deviations and can be used to screen data according to a user defined probability level (Hubbard, 2001b).

\section{Data Collection and Analysis}

For LIG thermometers, data collection involves manually reading the instruments. If the station has maximum and minimum thermometers, the readings should be taken at the same time every day (the recommendation is 0700 
LST) and the thermometers reset. The observer should be sure to position the eye in the horizontal plane that intersects the end of the liquid column and normal to the vertical plane of the thermometer. This will ensure that the scale is viewed in proper perspective to the mercury column. Data collection from sensors connected to loggers can be retrieved as frequently as communication speed and cost allows. This can be accomplished using telephone lines, cell phones (Brown et al., 2001; Grant \& Toby, 2001), radio, satellite technology, or direct Internet linkage (Robbins et al., 2001). The data are checked for validity as soon as they are collected to identify any sensors that have failed. These checks are done by creating serial plots of the observations, or by specially written computer programs that check the differences among neighboring observations at the same time.

\section{Application to Agricultural Systems}

Where crops, insects, and animals live is determined largely by the temperature microclimate. In agricultural systems, temperature is used as an indication of when crops should be planted. For example, corn (Zea mays L.) will not grow well when the temperature is below $10^{\circ} \mathrm{C}$; therefore, corn is generally planted only after the soil reaches or exceeds a temperature of $10^{\circ} \mathrm{C}$. Cool season crops such as wheat (Triticum aestivum L.) can grow when temperatures exceed $0^{\circ} \mathrm{C}$. Insects that overwinter in a locale also require the temperature to be above a lower threshold in order to grow and reproduce. The cardinal temperatures-the minimum, optimum, and maximum temperature for an organism-can be used to define the suitability of the temperature environment for that organism. When the temperature either exceeds or falls below the optimum temperature, the organism will begin to experience a temperature stress. The minimum and maximum cardinal temperatures are the point where an organism will begin to experience severe stress and, if left in that environment, will eventually die.

For spring-planted crops in mid-latitudes, the length of a growing season is defined as the period between the date of the last spring temperature of $0^{\circ} \mathrm{C}$ and the date of the first autumn temperature of $0^{\circ} \mathrm{C}$. During this period, plants are able to grow and reproduce. Perennials often break dormancy before the last spring temperature of $0^{\circ} \mathrm{C}$, but they are subject to damage if the temperature falls below $0^{\circ} \mathrm{C}$ after they initiate growth. If they are in the process of flowering when the temperature falls below $0^{\circ} \mathrm{C}$, they may fail to reproduce. Temperature helps determine the winter hardiness of a plant. A plant that has been subjected to a temperature below $5^{\circ} \mathrm{C}$ for a period of time may be able to survive temperatures well below $0^{\circ} \mathrm{C}$ whereas the same plant subjected to below-freezing temperatures without proper hardening (the term for a period of exposure to temperatures slightly above zero) may be severely injured or killed. Many perennials will not flower profusely in the spring if they have not experienced enough hours between 0 and $5^{\circ} \mathrm{C}$. These temperatures are called chilling temperatures. Many fruit crops require a minimum number of hours at these chilling temperatures. The number of hours required are called chilling hours. How rapidly a plant or insect develops is often determined by temperature. The growing degree unit has been developed as one method of measuring the rate of plant development. This unit is defined by

$\mathrm{GDU}=\left(T_{\mathrm{h}}+T_{1}\right) / 2-T_{\mathrm{b}}$ 
where $T_{\mathrm{h}}$ is the daily maximum temperature, $T_{1}$ is the daily minimum temperature, and $T_{\mathrm{b}}$ is a base temperature below which a plant or insect is not assumed to develop. In some cases, $T_{\mathrm{h}}$ is limited to an upper threshold temperature, and $T_{1}$ is limited to the base temperature. For example, in the commonly used modified growing degree day for corn, $T_{\mathrm{h}}$ is limited to $30^{\circ} \mathrm{C}$ if the daily maximum temperature is above $30^{\circ} \mathrm{C}$, and if the minimum temperature is below $10^{\circ} \mathrm{C}$, then $T_{1}$ is set to $10^{\circ} \mathrm{C}$. There is nothing magical about the growing degree unit, except that accumulation of GDUs correlates better to the rate of plant development than the number of days after the start of plant or insect growth. The accumulation of GDUs also is referred to as thermal time. Campbell and Norman (1998) present a more in-depth discussion of thermal time. Crops may be classified according to how many GDUs are required to reach maturity. An early season corn hybrid may require only $2100 \mathrm{GDU}$ to reach maturity, while a mid-length hybrid may require 2700 GDU and a late season hybrid may require 3200 GDU. Because of higher yields, the longer season hybrids are preferred but the risk of freezing during emergence or before maturity is a limiting factor. Accurate temperature records are necessary to assess the risk associated with various hybrids in any given area.

\section{PRECIPITATION}

Precipitation, in liquid and frozen form, is one of the more important weather variables for agricultural systems. To survive, all plants rely on water from precipitation to recharge the soil. Periods of no precipitation result in the development of drought, and periods of excess precipitation produce floods. Both extremes have a major impact on agricultural crops, livestock, and operations.

\section{History}

Middleton (1969) traces the first rain gauge to India in the 4th century B.C. Measuring of rainfall as a depth rather than as volume was reported as early as the 1st century A.D. (Horton, 1919). Rain gauges also were in use as early as 1442 in Korea, almost 200 years before the Italian Benedetto Castelli informed Galileo in a 1639 letter of his rainfall measurements (Kurtyka, 1953). Recording rain gauges were created early in the history of measuring rainfall in the Western world. The first tipping bucket rain gauge was invented by Sir Christopher Wren in England in 1662.

Kurtyka (1953) and Middleton (1969) provide reviews of the history of the rain gauge and its placement. Middleton (1969) describes the evolution of rain gauge construction, including recording rain gauges. Kurtyka (1953) discusses the differences in the construction of numerous rain gauges, and also discusses the issues and history of siting and protecting rain gauges.

With the advent of the computer age and microelectronics came electronic techniques to measure rainfall rate, quantity, and type. DeFelice (1998) describes the principle of some of the electronic techniques, and discusses the use of laser (optical rain gauges), radar, and satellite in estimating precipitation. The advantage of radar and satellite is their ability to show the spatial distribution of rainfall 
across a region. Considerable effort has been devoted to the calibration of radar for rainfall measurement. Still radar estimates of rainfall need to be checked against rain gauge estimates.

\section{Principle of Operation}

Liquid precipitation accumulation is usually measured by tipping bucket rain gauges or weighing rain gauges (Fig. 1-3). The principle of weighing gauges is based on the weight of accumulated precipitation on a spring-loaded platform. The position of a loaded balance can be used to indicate the liquid precipitation accumulation by a linear variable differential transformer (LVDT) sensor or a simple potentiometer. Voltage signals proportional to precipitation are obtained from the LVDT or potentiometer. Because of the high acquisition cost and greater long-term maintenance costs for the weighing gauge, tipping bucket rain gauges are currently more widely used (e.g., Texas Electronics, Model TR525I, Texas Electronics, Dallas, TX; and Friez Engineering Company, Model 7405HA, Belfort Instrument Co., Baltimore, MD).The tipping bucket is located under a funnel in the collector housing. The bucket is a two-chamber container that pivots. Precipitation flows through the funnel into one compartment until enough precipitation (e.g., $0.245 \mathrm{~mm}$ ) is present to tip that side of the bucket down. Thereupon it empties and the other side begins to fill. The weight that causes the bucket to tip on its pivots is the resolution of the gauge. The tipping motion activates a mercury switch (or reed switch), thereby establishing a momentary closure for each unit resolution of rain. The output from the tipping bucket is one electrical pulse for each unit resolution of precipitation collected.

One important source of error in the precipitation measurements of a tipping bucket rain gauge is related to precipitation intensity. High rainfall intensity causes incomplete dumping of the tipping bucket rain gauges. Increasing the volume of the tipping bucket can improve the rain intensity accuracy, but it will decrease the resolution of the rain gauge. Other sources of error are wetting loss and wind-induced errors (Metcalfe et al., 1997). Snowfall or other solid precipitation cannot be accurately accumulated into liquid precipitation by non-heated tipping rain gauges. Rain gauges that are heated to collect frozen precipitation can introduce an error in measurement. This error is an underestimation of the total precipitation due to the evaporation when the frozen precipitation drops or flakes hit the heated parts of the rain gauge.

\section{Instrumentation Usage}

Errors in measuring precipitation with gauges are caused by evaporation, adhesion of the water to the collection funnel, splash into or out of the collection funnel, inclination (i.e., rain gauge not level), and poor exposure. Errors due to evaporation, adhesion, inclination, and splash summed together represent errors in the range of $-1.5 \%$ (Kurtyka, 1953). Exposure errors can range from -5 to $-80 \%$. The errors associated with adhesion can be determined as part of the calibration procedures. Careful attention to rain gauge placement can reduce exposure errors. 


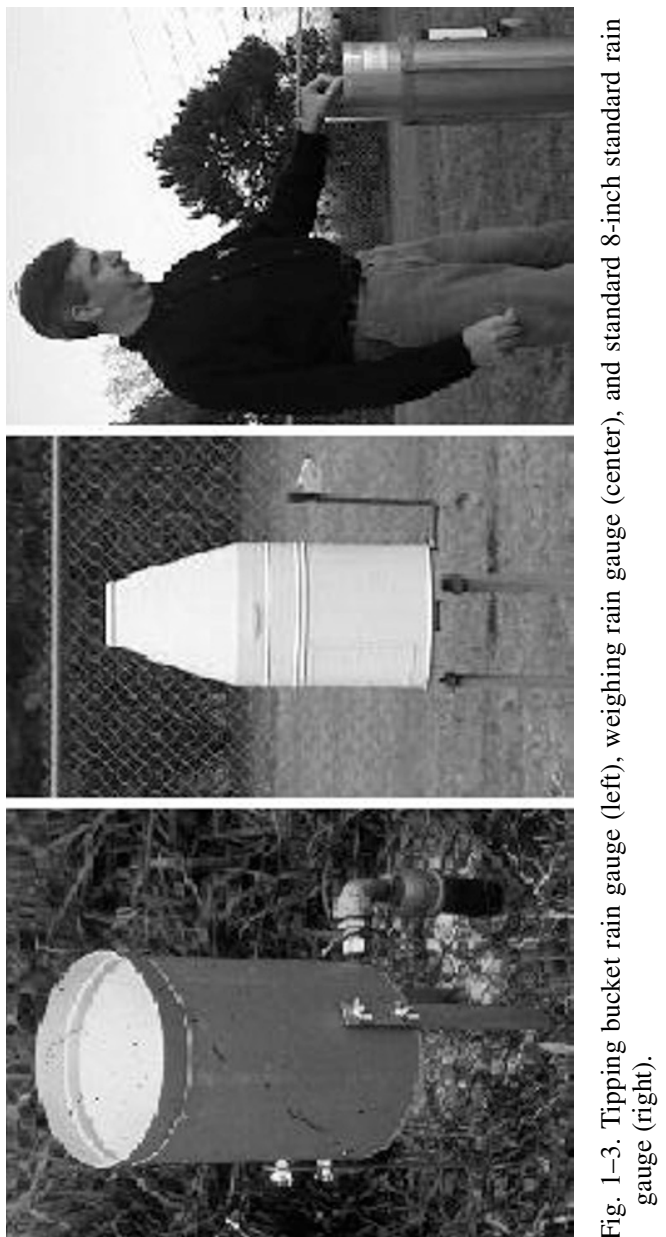




\section{Calibration}

Rain gauges (both tipping bucket and weighing rain gauges) are easily calibrated. Tipping bucket rain gauges can be calibrated by slowly pouring 10 times the water required for one unit resolution (one tip) into the rain gauge with a flow rate 10 tips per minute. The signal output must be $10 \pm 1$ pulses or $10 \pm 1$ tips to maintain sufficient accuracy of normal operation (1\% at 2 inches hour $^{-1}$ or better). Weighing bucket rain gauges can be calibrated with a set of weights that represent the presence of $25.4 \mathrm{~cm}$ increments of water. The weights are calibrated to the size of the collecting funnel.

Weighing bucket rain gauges should also be tested for sensitivity to small, low-intensity showers. This can be accomplished by adding a known quantity of water to the weighing bucket rain gauge with a titration burette, adding the water at a slow rate. This calibration will show the "stiffness" of the spring and its ability to respond to small changes in precipitation.

The quantity of precipitation that adheres to the collecting funnel can be determined as part of the calibration by slowly adding a known quantity of water to the collecting funnel and measuring the amount that passes through the funnel. Care should be taken to ensure that all the surface of the collecting funnel is wetted. The difference between the amount of water added to the funnel and the water collected from the funnel provides estimates of the smallest precipitation event that will be measured, and the underestimate of a recorded precipitation event.

\section{Placement}

Placement of the rain gauge is critical to accurate rainfall measurements. Factors that need to be considered are location of rain gauge in landscape, the height of the rain gauge opening above the surface, and inclination of rain gauge (i.e., the tilt of the rain gauge from vertical). If the collection funnel of the rain gauge is not level, the rain gauge will tend to over-collect rainfall when the tilt is pointing upwind, and under-collect when the tilt is downwind.

Rain gauges should be located on the earth's surface away from obstructions such as buildings, trees, and wind breaks. Obstructions develop eddies that result in increased turbulence at the rain gauge and/or sheltering of the rain gauge from rain. Windbreaks should be at least 20 times the height of the windbreak from the rain gauge to ensure no shelter effects at the rain gauge.

The elevation of the collection funnel above the surface of the earth affects the quantity of rain collected. As the elevation of the rain gauge increases above the earth's surface, the quantity of rain collected decreases. This is due to greater turbulence and wind speed with elevation. Studies have shown that a rain gauge mounted on the edge of a building roof results in significant under catch of precipitation, especially when the rain gauge is on the upwind edge of the roof (Kurtyka, 1953). To compare stations within a network, the height of the rain gauge, above the local surface elevation, should be constant. Otherwise, an under-collection at one station may be a result of the rain gauge height rather than less rainfall.

Accurate snowfall (and to a lesser extent rainfall) measurement requires the installation of a wind-shield around the rain gauge. There are two main types of wind-shields for rain gauges. One is the Nipher shield (Middleton \& Spilhaus, 
1953) and the other is the Alter shield. The purpose of the shields is to ensure a horizontal wind over the collection funnel. The Nipher shield, developed in 1878, is trumpet shaped but is not recommended for unattended use because snow tends to build up in the shield and contaminate the precipitation measurements. The Alter shield is a series of independent baffles hanging from a ring that surrounds the rain gauge. The baffles deflect the wind down toward the ground and do not collect snow. This is the shield that is generally used at NWS stations in the USA. Errors associated with precipitation catches from unshielded rain gauges can be as high as $20 \%$ for rain events, $60 \%$ for mixed precipitation events, and $>90 \%$ for snow events (Hanson, 1989). In a World Meteorological Organization (WMO) intercomparison of rain gauges and shields, the reference shield was an octagonal vertical double fence intercomparison reference (Yang et al., 1998). When it is desirable to remove as much of the "wind effect" as possible, three concentric shields are installed surrounding the rain gauge. This set-up is known in the USA as the Wyoming shield and is particularly suited for snow measurement.

\section{Maintenance}

Accurate rainfall measurements require special attention to rain gauge maintenance. The rain gauge and its mechanical mechanism must be kept clean and well lubricated. The lubricant must not thicken at cold temperatures. Dust on the collection funnel will increase the adhesiveness of the funnel, resulting in underestimation of precipitation events. If dust is present, the rain gauge will lose its sensitivity to light precipitation events. Each time a station is visited the rain gauge should be checked to be sure it is level.

Weighing bucket rain gauges can be winterized by removing the funnel portion of the collector and adding some environmentally safe antifreeze in the bucket. The snow or freezing rain will melt as it contacts the antifreeze solution in the rain gauge and the increase in weight is a relatively accurate measure of the water in the frozen precipitation event.

Evaporation from a weighing bucket rain gauge can be reduced by adding vegetable oil to the bucket. The oil will float on top of the water and prevent evaporation. If this practice is adopted, the rain gauge should be frequently checked for dead insects and other debris. Insects and debris should be removed and the bucket cleaned. After cleaning, fresh oil should be added to the bucket.

\section{Data Collection and Analysis}

Data collection from manual rain gauges involves measuring the depth of water in the collection tube. If the precipitation event involves frozen precipitation, the snow or ice inside the collection funnel must be melted before the measurement is taken. With either tipping bucket or weighing bucket rain gauges, data collection is accomplished using a data logger. The data are downloaded periodically, and the data scrutinized for possible errors.

Analysis of tipping bucket measurements involves an assessment of the reasonableness of the precipitation event amount. Unlike the tipping bucket precipitation measurement, which is read directly from the data logger, weighing bucket measurements require a computation of rainfall within any given time 
period. The precipitation within the collection period is computed by subtracting the previous period's bucket weight from the current period's weight. In practice this will sometimes result in a negative rainfall value for a time period. The negative value is due to either evaporation from the bucket or wind buffeting of the rain gauge. If the cause is wind, frequent "phantom precipitation" events will be recorded even on clear days. Therefore, small precipitation events need to be checked carefully to ensure they are real events.

\section{Quality Assurance-Quality Control}

The discontinuous nature of precipitation and its high spatial variability make it more difficult to quality control. A limit test can be performed based on a user-defined precipitation limit. The precipitation limit may be taken, for example, as the precipitation associated with a return period of 100 years. The values exceeding this amount can be flagged for further examination. A second gauge at the site can be used to quality control precipitation, but generally gauges at nearby stations are too far away to be of use. Double mass analysis (Linacre, 1992) between two rain gauges can be used to identify the point in time when a discontinuity was introduced (wrong calibration coefficients, station move, change in gauge type, etc.).

\section{Application to Agricultural Systems}

Precipitation is the main limiting factor in crop production. Therefore, precipitation measurements are used by agricultural managers and government officials to assess rainfed crop yields or to determine irrigation water allotments and timing of irrigation. Precipitation form, rate, and amount determine the amount of infiltration into the soil and runoff from the soil surface, and thus in part govern the amount of soil erosion by water that will occur at a location. Precipitation data also are the backbone of drought monitoring efforts. Long-term precipitation records provide the data necessary to plan sustainable agriculture and erosion control practices.

\section{BAROMETRIC PRESSURE}

\section{History}

The first barometers were developed in the 17th century, with important contributions from Berti, Torricelli, Descartes, Pascal, and others (Middleton, 1969). Because of the small and slow changes of the height of a mercury column in a tube in response to atmospheric pressure changes, the first barometers were generally made with two liquids to magnify the changes. These barometers relied on either hydrostatic equilibrium or the gas laws. The reader is referred to Middleton (1969) for a detailed discussion about the early types of barometers.

Aneroid (the prefix $a$ meaning without; neros, a liquid) barometers rely on the measurement of force exerted by the atmosphere on some area of a mechanical system rather than on either hydrostatic equilibrium or the gas laws. Blaise 
Pascal suggested using a dead weight connected to a closed and sealed bellows with one end fastened to a roof beam and a heavy chain hung from the other. Johann Bernouilli in 1698 also suggested the use of "closed bellows that would compress and dilate by itself, as the weight of the air increases or decreases." Robert Boyle suggested using a dead weight connected to the piston of an air pump with the piston pushed to the end of the cylinder and the valve closed. Neither of these methods were immediately used. The aneroid barometer relies on the elasticity of solid materials. The first satisfactory metallic barometer was developed in 1843 by Lucien Vidie, an engineer from Nantes, France.

Aneroid barometers are widely used in automated weather stations. Precision barometers have been developed in the past 30 years using quartz crystal resonator technology (Paros, 1973). These instruments use a precision quartz crystal resonator whose frequency of oscillation varies with pressure-induced stress.

\section{Principle of Operation}

Most pressure sensors today do not use the old-fashioned "fluid barometer" principle where the height of a column of liquid is measured as an indicator of pressure. Instead, aneroid barometers with capacitive sensing mechanisms are employed to realize pressure changes in the atmosphere. Although this mechanism is inherently nonlinear (since the capacitance is inversely proportional to gap width), the near zero temperature coefficient of the capacitive sensing mechanism is very attractive. The heart of the metal capacitive pressure sensor is the capacitive cell. The capacitive cell consists of two cell halves, each with a fixed capacitor plate, a flexible center diaphragm that senses the pressure variations, and two isolating diaphragms that are backfilled with oil to the sensing diaphragm. Similarly, the silicon capacitive pressure sensor has the same basic design as the metal sensor. The capacity of sensor $(C)$ is a function of the distance between plates $(d)$, area of plates $(A)$, and dielectric constant of the insulating material $(K)$. The capacity can be calculated as follows:

$$
C=\frac{K A}{4 \pi d}
$$

Typical capacitive pressure sensors used in weather stations include the Vaisala PBT101B (silicon type; Vaisala Inc., Woburn, MA) and Setra Model 470 (metal type; Setra Systems Company, Boxborough, MA). Both are called barometric pressure sensors. The barometric pressure refers to the actual pressure sensor value. The accuracy of barometric pressure sensors is strongly associated with their linearity (Lin), hysteresis (Hyst), repeatability (Rep), offset temperature coefficient (offset TC), and span temperature coefficient (span TC). The total accuracy is the root-sum-square (RSS) of each error (Tandeske, 1991):

$$
\text { RSS Error }= \pm \sqrt{(\text { Lin })^{2}+(\text { Hyst })^{2}+(\text { Rep })^{2}+(\text { Offset TC })^{2}+(\text { Span TC })^{2}}
$$

Each error usually is expressed in terms of percentage of full-scale range (FS) - e.g., $0.2 \%$ FS under certain temperature ranges. Although the capacitive 
pressure sensor has a good temperature coefficient compared with other sensor types, such as the piezoresistive or piezoelectric pressure sensors, the thermal effect is still an important factor that affects the barometric pressure readings.

\section{Instrumentation Usage}

Calibration of barometers used in the field is generally done at the factory; however, it is important to periodically check the calibration using portable NIST traceable precision barometers such as the Paroscientific Model 760 (Paroscientifc Inc., Redmond, WA). Laboratory calibration of aneroid barometers requires the use of pressure chambers where the pressure can be accurately regulated.

The placement of aneroid barometers in the field is critical to accurate pressure measurements. Pressure measurement errors are caused by wind, uncertainty in the temperature of the instrument, and instrument motion (DeFelice, 1998). To minimize these effects the sensor must be rigidly mounted in a location where it will not experience rapid temperature changes and where it is protected from the dynamic pressure of the wind. The elevation of the aneroid barometer should be recorded so that the pressure can be corrected to sea level for comparison with neighboring stations.

\section{Data Collection and Analysis}

Pressure measurements are corrected for altitude in order that comparison can be made with neighboring stations. For example, a station near sea level on an island in the ocean will show a higher pressure than a neighboring station located on the summit of a mountain only several miles away. This difference is in large part due to the difference in altitude of the two stations, and does not in itself indicate that a weather system is present. Barometric pressure measurements when corrected for altitude are used to determine the atmospheric pressure differences due to weather systems, not altitude. Many pressure units are widely used today. Some unit conversion factors are listed in Table 1-2.

\section{Quality Assurance-Quality Control}

In general, the same quality control procedures discussed for temperature can be used for pressure. The station pressure fields at a reference height also can be mapped to see if the measurements are consistent with existing weather patterns.

\section{Application to Agricultural Systems}

Atmospheric pressure measurements are indirectly applied to agricultural systems. Unlike temperature, where there is a clear and obvious effect on agricultural systems, atmospheric pressure has a secondary effect. Atmosphere pressure along with temperature affects the absolute quantity of water that can be held in the atmosphere. Thus, pressure measurements are used in more accurate estimates of the water loss from crops and animals. 
Table 1-2. Pressure conversion factors relative to the SI unit, the Pascal (Pa).

\begin{tabular}{ll}
\hline Unit & Conversion to Pa \\
\hline $1 \mathrm{~A}$ (atmosphere) & $1.01325 \times 10^{5}$ \\
$1 \mathrm{~b}$ (bar) & $10^{5}$ \\
$1 \mathrm{mb}($ millibar $)=\mathrm{hPa}$ (hectoPa) & 100 \\
$1 \mathrm{Mb}($ microbar) & 0.1 \\
$1 \mathrm{in} \mathrm{H} 2 \mathrm{O}$ [inch of water $\left.\left(4^{\circ} \mathrm{C}\right)\right]$ & 249.08 \\
$1 \mathrm{mH} 2 \mathrm{O}$ [meter of water $\left.\left(4^{\circ} \mathrm{C}\right)\right]$ & 9806.6 \\
$1 \mathrm{inHg}$ [inch of mercury $\left.\left(0^{\circ} \mathrm{C}\right)\right]$ & 3386.4 \\
$1 \mathrm{mmHg}$ [millimeter of mercury $\left.\left(0^{\circ} \mathrm{C}\right)\right]$ & 133.32 \\
$1 \mathrm{MPa}($ mega pascal) & $10^{6}$ \\
$1 \mathrm{PSI}$ (pounds per square inch) & 6894.76 \\
$1 \mathrm{~N} \mathrm{~m}^{-2}$ (newtons per square meter) & 1 \\
\hline
\end{tabular}

The most obvious application to agriculture is the effect pressure gradients across a region have on the winds and weather that occur. As more automated weather station networks are developed, and the data collected become available to the National Weather Service, the barometric pressure measurements at these stations will provide additional pressure resolution for input to numeric weather prediction models, and thus improve real time weather forecasts.

\section{CLOUD CEILING HEIGHT}

Clouds are important to climate because they strongly modulate incoming solar and outgoing thermal radiation. As the source of precipitation, they also are a key element in the hydrologic cycle. Clouds are currently under intense scrutiny by researchers to gain a better understanding of their role in our environment. Most agriculture systems are not sensitive to cloud height. Aviation agriculture, which includes aerial spraying and photography, is an exception. In this case, knowledge of cloud ceiling height is critical to operation of the airplanes.

\section{History}

In the 17 th and 18 th centuries, cloud height and motion was measured using two observers, spaced a known distance apart, who measured the angle from their location to a single point on a cloud (Middleton, 1969). Trigonometry was then used to compute the height of the cloud. In the mid-19th century, mirror nephoscopes were used to determine cloud height. Other methods developed in the late 19th and early 20th centuries included triangulation between two stations (made possible by the invention of the telephone), searchlights, range finders, and pilot balloons tracked by theodolites or radio signals.

\section{Principle of Operation}

Modern instruments used to measure the cloud bottom heights generally employ pulsed diode laser Lidar (Light Detection And Ranging) technology, where short, powerful laser pulses are sent out in a vertical or slant direction. The 
directly backscattered light caused by molecules, aerosols (dust), and cloud (water or ice) particles in the atmosphere is measured as the laser pulses traverse the sky. A ceilometer (for example, Vaisala Models CT12K or CT25K, Vaisala Inc., Woburn, MA) measures the backscattered light intensity from a pulsed InGaAs diode laser $(905 \mathrm{~nm})$ as a function of distance. The operating principle of the $\mathrm{CT} 12 \mathrm{~K}$ or $\mathrm{CT} 25 \mathrm{~K}$ ceilometer is based on measurement of the time needed for a short pulse of light to traverse the atmosphere from the transmitter of the ceilometer to a backscattering cloud base and back to the receiver of the ceilometer. Because the total distance traveled includes a path from the transmitter to the cloud and back again, the height of the cloud (from the transmitter) is actually one-half of the total distance. The calculation can be expressed as:

$$
h=\frac{c t}{2}
$$

where the $h$ is the height of cloud, $c$ is the speed of light $\left(3 \times 10^{8} \mathrm{~m} \mathrm{~s}^{-1}\right)$, and $t$ is the time from the transmission to the reception. For example, a cloud detected $24.4 \mu$ s after transmission indicated a cloud at $3650 \mathrm{~m}$ above the ground surface.

\section{Instrumentation Usage}

\section{Calibration}

Two calibration procedures are used to verify and/or optimize performance of the Vaisala ceilometers. Factory calibrations include testing transmitted and received laser power, optical alignment, and pulse timing electronics. The results of these tests are available from the microprocessor in the sensor system, which can be accessed by users. The other calibration procedure is to calibrate the ceilometers by tipping the instrument to a near horizontal position and aiming the beam at an object located a known distance from the ceilometer ( $>100 \mathrm{~m}$ distance). The "instrument health" data in the output files are used to diagnose possible instrument malfunction and are of sufficient detail to pinpoint a failing or failed component or subsystem.

\section{Placement}

Operationally, ceilometers are placed to provide information in support of aircraft safety. Thus the ceilometer is located near the touchdown zone of a primary runway at many airports (ASOS, 1998). At large airports, a secondary cloud height indicator may be installed to help detect meteorological discontinuities in the vicinity of the airport. At small airports, the ceilometer may be colocated with other sensors near a center-field location or touchdown zone.

\section{Maintenance}

Laser ceilometers can be obtained with built-in capability to monitor transmitted output power, which should be checked to guard against timing errors. The master oscillator frequency and stability can be checked using external highquality frequency standards with the output power of the transmitter (WMO, 
1996). Typical routine maintenance includes cleaning the exposed optics and external covers and replacing air filters where cooling blowers are involved.

\section{Data Collection and Analysis}

The Acquisition Control Unit receives the signals from the ceilometer and in turn applies sophisticated time-averaging algorithms to interpret "cloud hit" information and determine the cloud height and amount. Cloud base "hits" from each pulse are assigned vertical data bins within the measurement range. A deep fog or precipitation may result in "unknown hits" where laser backscatter signals from various heights within the moisture field are returned. In these situations no distinct cloud base can be specified, instead the vertical visibility is reported.

\section{Quality Assurance-Quality Control}

Clouds are often discontinuous fields, so use of the quality control tests mentioned in the temperature section are not applicable. When soundings of the atmosphere are available, the lifting condensation level (LCL) can be calculated and departures of LCL from observed cloud base height can be examined to screen data. In addition, manual reports from ground observers and pilots can be used to provided quality assurance of the cloud height data.

\section{WIND SPEED AND DIRECTION}

Wind direction and speed are two variables of great interest to the meteorologist. It is these two variables that provide an indication of the weather to come. Agriculturalists are interested in the history of wind speed and direction, as these data are used to determine the location of different farm buildings relative to each other, and the design of wind breaks that protect the farmstead and livestock during the winter. Real-time wind speed and direction information is critical to the spraying of crops for weed and pest control.

\section{History}

Wind vanes to show the direction of the wind have been available since the first century B.C. Wind vanes have taken many forms, but the main feature of any vane is a flat piece of material on the end of a horizontal rod that is balanced on a vertical rod so that it can turn in any direction. One of the earliest vanes that indicated the wind direction inside a building was developed by Marcus Terentius Varro (Middleton, 1969). Modern wind vanes, used for meteorological purposes, generally take on the shape of an airplane vertical stabilizer.

DeFelice (1998) lists three categories of anemometers based on their principle of measurement. They are aerodynamic, thermodynamic, and frequency shift anemometers, and they were developed in that order.

The first anemometer, using the aerodynamic principle, was invented by Leon Battista Alberti (Middleton, 1969), and consisted of a swinging plate faced into the wind by a vane that had an arc so that the deflection of the plate could be 
measured. The English physicist Robert Hooke reinvented the swinging plate anemometer in 1664. In 1672, Hooke constructed an anemometer using the principle of the windmill. The wind speed was observed by the number of revolutions of the propeller using three punches to mark the 100th, 1000th, and 10000 th revolutions. This was an early version of what is now know as a propeller anemometer. The propeller anemometer is mounted on a shaft that includes a wind vane so that the propeller is always pointed into the wind.

At about the same time that Hooke invented the propeller anemometer, a Paris instrument maker, Rene Grillet, described an anemometer with a vertical axis (Middleton, 1969). This was the forerunner of the cup anemometer, a common anemometer still in use today. Advantages of the cup anemometer are its lack of response to turbulence, and its ability to work independent of wind direction.

The first anemometer using the principle of the "pitot tube," also an aerodynamic principle, was designed in the early 1700s by Pierre Daniel Huet, but it was never built (Middleton, 1969). It was not until 1732 that the pitot tube was invented, by Henri Pitot, for use in measuring the speed of water in streams. Pitot tube anemometers are not common today.

The most common thermodynamic anemometer is the hot-wire anemometer. It uses the cooling power of the wind to detect wind speed. Frequency shift anemometers include sonic, laser, and microwave anemometers. The sonic anemometer uses the shift in the speed of sound due to wind. During the mid- to late-1990s, two-dimensional sonic anemometers were created. These anemometers are able to measure both wind speed and direction with no moving parts. Laser anemometers are designed for use on satellites. Microwave anemometers are designed to measure the vertical profile of the wind field. The laser and microwave anemometers are designed to provide a more complete picture of the wind field in the atmosphere.

\section{Principle of Operation}

Wind speed sensors used for atmospheric measurements fall into two broad categories: mean wind speed sensors and instantaneous wind speed sensors. Rotation anemometers such as cup anemometers, propeller anemometers, and rotation vanes (Fig. 1-4) are the most common sensors for the mean wind speed measurements at the AWS. The hot-wire anemometers and sonic anemometers are instantaneous sensors traditionally used in atmospheric turbulence work. While mean wind speed sensors cannot be used for instantaneous wind speed measurements, they are suitable for wind speed measurements at AWS sites because they are rugged, dependable, and relatively inexpensive. Both cup and propeller anemometers and vanes depend on moving parts coming into dynamic equilibrium with the wind flow.

Cup and vane systems are marketed in a variety of shapes and forms. The most common configuration is a three-cup anemometer and direction vane mounted side by side at the ends of a T-shaped horizontal boom. Both rotate on vertical axes, so they are separated horizontally to avoid mutual interference. The advantage of the cup anemometer is that it can accept winds from any direction (only the directions blocked by the wind vanes and the supporting mast would be considered unfavorable). Currently the most popular designs for mean wind speed 


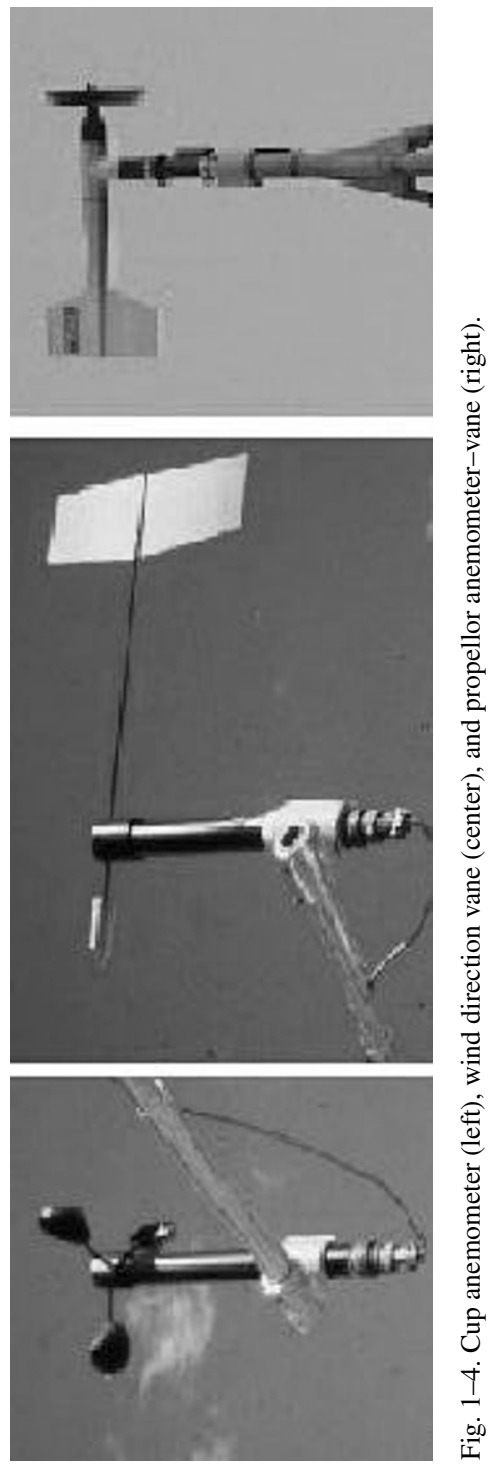


measurements by cup anemometers are (i) using a reed relay contact by a rotating magnetic field (e.g., Met One Instrument, Model 14A, Met-One Instruments, Inc., Grants Pass, OR), (ii) generating an alternating current (AC) sine wave voltage signal with frequency directly proportional to wind speed (NovaLynx Company, Model 200-03002, NovaLynx, Waterloo, Ontario, Canada), and (iii) using a photochopper device to provide a frequency output (NovaLynx Company, Model 200F460, NovaLynx, Waterloo, Ontario, Canada). The mean wind speed measured from the cup anemometer is a linear function of rotation frequency of the cup. For wind vanes with potentiometer systems that read vane position, the gap in the resistance element, typically a 5 or $10^{\circ}$ sector, is often pointed in the direction of the mast to keep the number of unfavorable directions to a minimum. Alternatively, the gap can be pointed to the north so that the readout from the potentiometer in degrees gives the wind direction without any further computation.

Several important specifications in wind speed sensors are angular response (cosine response or direction sensitivity), frequency response (combining the time constant and distant constant together), and starting speed (threshold). Cup anemometers can be periodically calibrated in laminar flow in a wind tunnel to obtain an accuracy of \pm 1 to $\pm 2 \%$. The distance constant (63\% response time constant converted to distance) is between 1.5 and $5 \mathrm{~m}$, and starting speeds are typically $0.5 \mathrm{~m} \mathrm{~s}^{-1}$. There is a tendency in cup anemometers to over speed, resulting partly from their nonlinear response to wind speeds due to their tendency to respond more quickly to an increase in wind speed than to a decrease in wind speed. Reports of over speeding error generally range from 5 to $10 \%$, depending on the intensity of turbulence (sometimes it can reach 30\%) (Izumi \& Barad, 1970; Busch \& Kristensen, 1976; Kaganov \& Maglom, 1975; Wyngaard, 1981).

Propeller anemometers either use a reed relay similar to the cup anemometer, or a voltage generator powered by the anemometer. While cup anemometers tend to over speed in highly turbulent conditions, propeller anemometers tend to under speed in turbulent conditions. This is the result of the faster response of the propellers to eddies $180^{\circ}$ from the mean wind direction.

\section{Instrumentation Usage}

\section{Calibration}

Anemometer calibration should ideally be conducted inside wind tunnels. When these facilities are not available, the anemometers may be checked using a constant speed motor to turn the shaft. This will test the electronics used to compute the wind speed. With propeller anemometers, a torque gauge can be used to determine the force needed to determine the minimum start speed. Alternatively, group calibration of anemometers in the atmosphere may be used provided a "high" quality anemometer with known calibration is used as the standard.

\section{Placement}

Placement of an anemometer is critical to accurate measurement of the mean wind speed and true wind direction of a location. The standard height for anemometers is $10 \mathrm{~m}$ (WMO, 1996). An ideal location for an anemometer is over flat terrain with vegetation of constant height. Such locations are seldom avail- 
able, so compromises in location are the rule rather than the exception. Therefore, some guidelines need to be followed in locating anemometers. A primary guideline is to maintain a ratio of at least 10 between the distance from the anemometer to any obstacle and the height of the obstacle. In practice, obstructions affect the downwind air flow at much greater distances than 10 times the obstruction's height (Hollinger \& Scott, 2001). Thus, the further away from obstructions an anemometer can be placed the better the location and the more representative the wind measurement.

\section{Maintenance}

Cup and propeller anemometers and vanes are susceptible to bearing wear and also to freezing during freezing rain events. Periodic maintenance includes bearing replacement and keeping the instruments clean and dry. Anemometers in the field should be periodically checked using an independent anemometer standard to detect early bearing failure.

\section{Data Collection and Analysis}

Data collection is best accomplished by use of a data logger to record the wind data. Routine checks of the data should be undertaken. The wind measurements should include the mean wind speed, standard deviation of the direction, and the magnitude and direction of the peak gust. Wind speeds are highly variable from one time period to another, so any consecutive time periods with exactly the same wind speed should be checked for validity. Generally, the only time this will occur is during calm conditions or when the wind speed is below the anemometer's threshold speed. When computing the mean wind direction, the instantaneous wind vectors must be computed and the resultant vector direction recorded. This practice is necessary to accurately compute the mean wind direction. The error in averaging can lead to misleading results. Consider the case when the wind is from the north. The potential exists to average, for example, 355 and $5^{\circ}$, both northerly wind directions, but when arithmetically averaged yield $180^{\circ}$, a southerly wind direction. The vector resultant is $0^{\circ}$, which is still a northerly direction.

\section{Quality Assurance-Quality Control}

Some of the same tests described for temperature can be used with wind speed and direction data. Limits are particularly useful, while rate of change is not applicable to wind direction. In some weather patterns, the site-to-site comparisons are quite useful, but in others the comparisons are useless. The wind speed and direction can also be compared with that indicated by a mesoscale wind pattern analysis. Experience and expertise on the part of the data analyst are paramount to successful quality assurance of wind data. 


\section{Application to Agricultural Systems}

Winds benefit and harm agricultural systems. Wind currents transport pollen that ensures the fertilization of self-pollinated crops. At the same time, wind currents may carry chemicals that are being sprayed on a field to neighboring fields or farmsteads, possibly resulting in damage to animals or other plants. Winds provide ventilation for livestock buildings, cool animals in the summer, and disperse odors. In the winter, winds associated with snow or ice can be fatal to livestock. Strong winds can damage crops and farm structures. Winds also transport insects from one region of the country to another. These insects often carry diseases that then infect the crop as the insects feed on the crop.

Historical wind data can be applied to the planning and design of large livestock operations. Agricultural odors are not acceptable to the non-agricultural community and therefore create controversy when experienced in non-rural settings. The frequency and intensity of odor can be related to wind climatologies. Typically, a dual frequency analysis is used to examine the percentage of time that the wind is from each direction for given intervals of wind speed. A minimum of eight direction categories, (N, NE, E, SE, S, etc.) are used but more directions can be included for more detail. Light wind speeds tend to move odors along the surface with little mixing, resulting in a concentration of the odors and complaints. Stronger winds tend to be more turbulent and the odors are mixed and carried up and away from the surface. In this case they are not as much of a problem.

\section{Site Requirements}

Collection of representative meteorological data is critical to agricultural applications. Therefore, careful attention must be paid to where a station is located within a region or landscape. Where a station should be located is dependent on the purpose for which the meteorological data are being collected. If the purpose of the data is to infer weather conditions at locations remote from the site, then the station should be located in an area representative of the general region.

Ideally, a station should be located in an open area where the instruments are not affected by vegetation or manmade obstructions (Fig. 1-5). The vegetation over which the instruments are located should represent the general vegetation of the area. In most cases the ideal surface is a grass surface with the grass maintained at a height not to exceed $10 \mathrm{~cm}$; however, if the station is located in a desert area, the surface under the instruments should be left bare. In all cases, the vegetation should be maintained at a height such that the instruments that measure atmospheric variables (temperature, precipitation, relative humidity, solar radiation) are located approximately 1 to $2 \mathrm{~m}$ above the top of the vegetation.

When measuring wind and solar radiation, care must be taken to ensure that the instruments are not shaded by manmade structures or tall vegetation. The dome of the radiometers used to measure solar radiation should have a clear view of the horizon and the sky in all directions. This is often not possible because of the structures necessary to mount all the instruments at a station. Generally, 


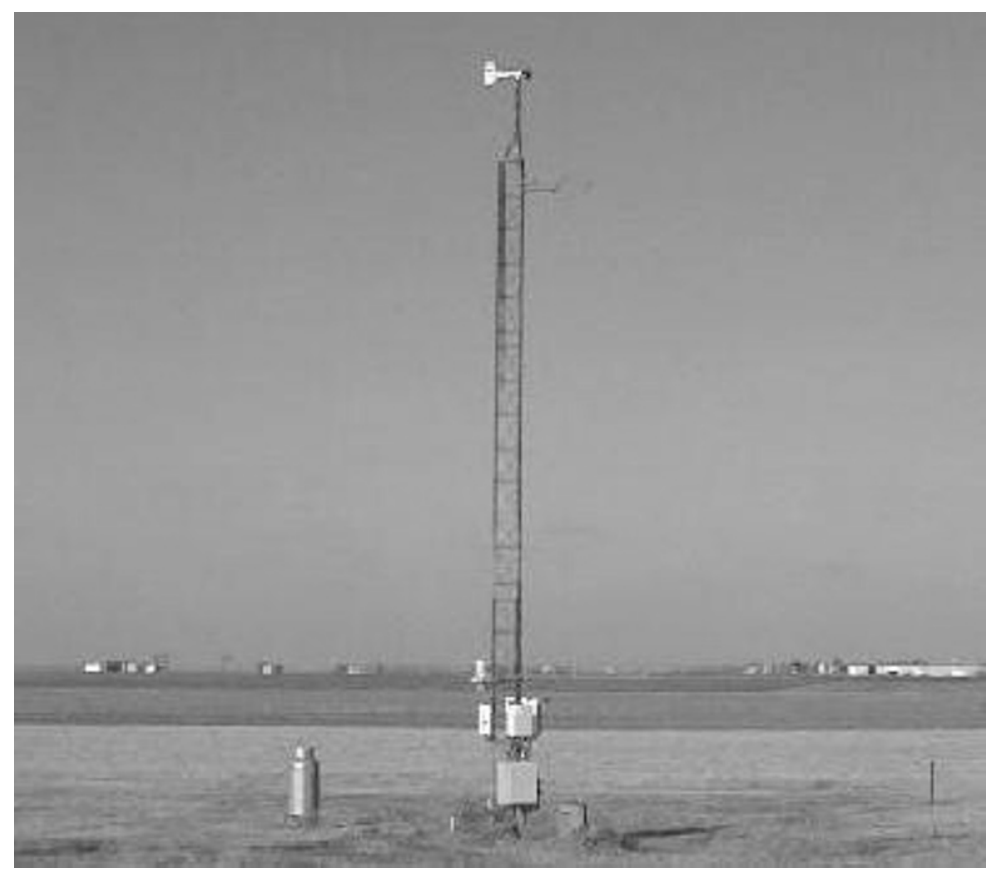

Fig. 1-5. A typical automated weather station, Bondville, IL.

obstructions to radiation measurements will not be a problem if the obstruction does not occupy $>1 \%$ of the sky hemisphere.

Siting of wind instruments is critical to accurate measurement of synoptic winds. Standards for wind instrument siting are provided by the World Meteorological Organization (WMO, 1996). Hollinger and Scott (2001) describe effects of obstructions on wind measurements at some automated stations in Illinois.

\section{SUMMARY}

The variety of options for choosing meteorological sensors has increased significantly as a result of the emergence of new sensors and the requirements of new applications. A sensor type usually has individually inherent advantages and disadvantages, depending on specific applications; however, consideration of the required accuracy and stability of sensors, ease of maintenance, and comparative cost may help the user make an informed decision on sensor selection. The measurement errors of a sensor generally propagate in an additive fashion. Consequently, the total error for a measurement system equals the root mean square of each independent error component. Therefore, the sensor accuracy cannot represent the measurement errors that are inherent in the environmental changes, degree of coupling to the atmosphere, installation problems, periodical calibration and maintenance, and data acquisition system (datalogger). Preventive and 
periodic sensor testing is the best way to ensure collection of high-quality data from the AWS networks.

\section{REFERENCES}

AASHTO, 1999. Weather information systems. Guide for snow and ice control. Am. Assoc. of State Highway and Transportation Officials, Washington, DC.

ASOS, 1998. Automated surface observing system user's guide. National Weather Service, NOAA, Silver Spring, MD.

Brown, P.W., and K.G. Hubbard. 2001. Lessons from the North American experience with automated weather stations. In K.G. Hubbard and M.V.K. Sivakumar (ed.) Automated weather stations for applications in agriculture and water resources management: Current use and future perspectives. World Meteorological Organization, Geneva, Switzerland.

Brown, P.W., T. Machibya, and B.T. Russell. 2001. Use of cell phones for data retrieval in Arizona. In K.G. Hubbard and M.V.K. Sivakumar (ed.) Automated weather stations for applications in agriculture and water resources management: Current use and future perspectives. World Meteorological Organization, Geneva, Switzerland.

Busch, N.E., and L. Kristensen. 1976. Cup anemometer over speeding. J. Appl. Meteorol. 15:1328-1332.

Campbell, G.S., and G.R. Diak. 2005. Net and thermal radiation estimation and measurement. p. 59-92. In J.L. Hatfield and J.M Baker. Micometeorology in agricultural systems. ASA Agron. Monogr. 47. ASA, CSSA, SSSA, Madison, WI.

Campbell, G.S., and J.M. Norman. 1998. An introduction to environmental biophysics. 2nd ed. Springer-Verlag, New York.

Dally, J.W., W.F. Riley, and K.G. McConnell. 1984. Instrumentation for engineering measurements. John Wiley \& Sons, New York.

DeFelice, T.P. 1998. An introduction to meteorological instrumentation and measurement. Prentice Hall, Upper Saddle River, NJ.

Edwards, J.B. 1998. The relationship between road accident severity and recorded weatherexploratory analysis of road accidents. J. Safety Res. 29:249-262.

Friday, E.W. 1994. The modernization and associated restructuring of the National Weather Service: An overview. Bull. Am. Meteorol. Soc. 75:43-52.

Fritschen, L.J., and L.W. Gay. 1979. Environmental instrumentation. Springer-Verlag, New York.

Grant, R.H., and D. Toby. 2001. Cellular communications for automated weather stations. In K.G. Hubbard and M.V.K. Sivakumar (ed.) Automated weather stations for applications in agriculture and water resources management: Current use and future perspectives. World Meteorological Organization, Geneva, Switzerland.

Hanson, C.L. 1989. Precipitation catch measurement by the Wyoming shield and the dual-gage system. Water Res. Bull. 25:159-164.

Hauptmann, P. 1993. Sensors: Principles and applications. Carl Hanser, Munich.

Hollinger, S.E., B.C. Reinke, and R.A. Peppler. 1994. Illinois Climate Network: Site descriptions, instrumentation and data management. Illinois State Water Survey, Champaign, IL.

Hollinger, S.E., and R.W. Scott. 2001. Station wind characterization. In K.G. Hubbard and M.V.K. Sivakumar (ed.) Automated weather stations for applications in agriculture and water resources management: Current use and future perspectives. World Meteorological Organization, Geneva, Switzerland.

Horton, R.E. 1919. The measurement of rainfall and snow. J. New England Water Works Assoc. $33: 14-21$.

Hubbard, K.G. 2001a. The Nebraska and High Plains regional experience with automated weather stations. In K.G. Hubbard and M.V.K. Sivakumar (ed.) Automated weather stations for applications in agriculture and water resources management: Current use and future perspectives. World Meteorological Organization, Geneva, Switzerland.

Hubbard, K.G. 2001b. Multiple station quality control procedures. In K.G. Hubbard and M.V.K. Sivakumar (ed.) Automated weather stations for applications in agriculture and water resources management: Current use and future perspectives. World Meteorological Organization, Geneva, Switzerland.

Hubbard, K.G., and M.V.K. Sivakumar (ed). 2001. Automated weather stations for applications in agriculture and water resources management: Current use and future perspectives. World Meteorological Organization, Geneva, Switzerland. 
Izumi, Y., and M.L. Barad. 1970. Wind speeds as measured by cup and sonic anemometers and influenced by tower structure. J. Appl. Meteorol. 9:851-856.

Kaganov, E.I., and A.M. Yaglom. 1975. Errors in wind-speed measurements by rotation anemometers. Boundary-Layer Meteorol. 10:15-34.

Klassen, S., and B. Bugbee. 2005. Shortwave radiation. p. 43-58. In J.L. Hatfield and J.M Baker. Micometeorology in agricultural systems. ASA Agron. Monogr. 47. ASA, CSSA, SSSA, Madison, WI.

Kurtyka, J.C. 1953. Precipitation measurement studies. Illinois State Water Survey Report of Investigation no. 20. Illinois State Water Survey, Champaign, IL.

Lin, X. 1999. Mircoclimate inside air temperature radiation shields. Ph.D. diss. Univ. of Nebraska, Lincoln.

Linacre, E. 1992. Climate data and resources: A reference and guide. Routledge, New York.

Marshall, B., and F.I. Woodward. 1985. Instrumentation for environmental physiology. Seminar Series 22. Society for Experimental Biology. Cambridge Univ. Press, Cambridge.

Meek, D.W., and J.L. Hatfield. 2001. Single station quality control procedures. In K.G. Hubbard and M.V.K. Sivakumar (ed.) Automated weather stations for applications in agriculture and water resources management: Current use and future perspectives. World Meteorological Organization, Geneva, Switzerland.

Metcalfe, J.R., B. Routledge, and K. Devine. 1997. Rainfall measurement in Canada: Changing observational methods and archive adjustment procedures. J. Climate. 10:92-101.

Meyer, S.J., and K.G. Hubbard. 1992. Nonfederal automated weather stations and networks in the United states and Canada: A preliminary survey. Bull. Am. Meteorol. Soc. 73:449-457.

Middleton, W.E. Knowles. 1966. A history of the thermometer and its use in meteorology. Johns Hopkins Press, Baltimore, MD.

Middleton, W.E. Knowles. 1969. Invention of the meteorological instruments. Johns Hopkins Press, Baltimore, MD.

Middleton, W.E. Knowles, and A.F. Spilhaus. 1953. Meteorological instruments. 3rd ed. Revised. Univ. of Toronto Press, Toronto, Canada.

Paros, J.M. 1973. Precision digital pressure transducer. ISA Trans. 12:173-179.

Robbins, K., J. Finney, and A. Simmons. 2001. Direct linkage to stations through the Internet. In K.G. Hubbard and M.V.K. Sivakumar (ed.) Automated weather stations for applications in agriculture and water resources management: Current use and future perspectives. World Meteorological Organization, Geneva, Switzerland.

Steinhart, J.S., and S.R. Hart. 1968. Calibration curves for thermistors. Deep Sea Res. 15:497.

Tandeske, D. 1991. Pressure sensors: Selection and application. Marcel Dekker, New York.

Tanner, B.D. 1990. Automated weather stations. Remote Sensing Rev. 5(1):73-98.

World Meteorological Organization. 1996. Guide to meteorological instruments and methods of observation. 6th ed. WMO no. 8. WMO, Geneva, Switzerland.

Wyngaard, J.C. 1981. Cup, propeller, vane, and sonic anemometers in turbulence research. Ann. Rev. Fluid Mech. 13:399-423.

Yang, D., B.E. Goodison, J.R. Metcalfe, V.S. Golubev, R. Bates, T. Pangburn, C.L. Hanson. 1998. Accuracy of NWS 8" standard nonrecording precipitation gauge: Results and application of WMO intercomparison. J. Atmos. Oceanic Technol. 15:54-68. 